\title{
Measuring density and Young's modulus of a log through the vibration test without measuring its weight
}

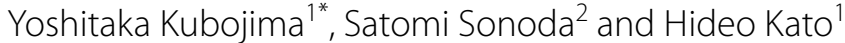

\begin{abstract}
This study examines a simple estimation method for the measurement of the mass of an on-site log through a vibration test. In this method, rather than the log itself, a cut end portion is weighed. For this purpose, the vibration method with additional mass (VAM) was applied to Sitka spruce (Picea sitchensis Carr.) circular truncated cones (model log) and Japanese cedar (Cryptomeria japonica D. Don) logs. Longitudinal vibration tests were performed on the circular truncated cones with/without an additional mass. Furthermore, the cut end portions of the circular truncated cones and logs were used as the virtual additional mass in the VAM. From the results of the vibration test using specimens with/without the concentrated mass, it is possible to estimate the mass of a circular truncated cone with 10\% error by the VAM. The cut end portion of a circular truncated cone could be used as the virtual mass in the VAM. From the experimental and theoretical results, to maintain high estimation accuracy, the specimen length must not be too short as shown in our previous study for a specimen with constant cross-sectional shape. The cut end portion of the logs could be used for the virtual mass of the VAM.
\end{abstract}

Keywords: Circular truncated cone, End cutting, Log, Vibration method with additional mass, Weighing

\section{Introduction}

When logs are bought in log markets, stable qualities of the logs, in other words, appropriate classifying based on log shapes such as diameter, length and warp is required. Since timber quality is affected by its Young's modulus, classifying logs based on the Young's modulus enables to enrich lineups of log markets. Evaluating the Young's modulus of a log before sawmilling allows it to be sold at a high value. However, the Young's modulus of logs cannot be estimated from the evaluation based on the shape.

In classifying lines at log markets and large-scale sawmilling factories, the shape of logs on a conveyor is measured and the logs are consequently classified. Although there is a classifying process having a scale and a tapping system to measure the mass and Young's modulus

\footnotetext{
*Correspondence: kubojima@ffpri.affrc.go.jp

${ }^{1}$ Forestry and Forest Products Research Institute, 1 Matsunosato, Tsukuba, Ibaraki 305-8687, Japan

Full list of author information is available at the end of the article
}

of the logs, the process reduces the production efficiency. Because a log is large and heavy, handling it is difficult, and determining the output of a scale is time consuming. Hence, a method to measure the mass of a $\log$ in short time is desirable.

Because logs have an extra length of about $100 \mathrm{~mm}$ with respect to the nominal length, use of the extra length portion was examined in this study. It is possible that the density of the cut extra length portion is regarded as the density of a whole log. However, the measurement of the accurate volume of the cut end portion (the extra length portion) will be difficult because the shape of the butt end of a log is irregular due to swelled butt, notches and backcuts in felling. On the other hand, an inexpensive scale with high accuracy that is easy and safe to handle can be used for the cut end portion that is much smaller than the main body of a log. Weighing the cut end portion does not cause a serious reduction of the production efficiency.
Springer Open

(c) The Author(s) 2021. This article is licensed under a Creative Commons Attribution 4.0 International License, which permits use, sharing, adaptation, distribution and reproduction in any medium or format, as long as you give appropriate credit to the original author(s) and the source, provide a link to the Creative Commons licence, and indicate if changes were made. The images or other third party material in this article are included in the article's Creative Commons licence, unless indicated otherwise in a credit line to the material. If material is not included in the article's Creative Commons licence and your intended use is not permitted by statutory regulation or exceeds the permitted use, you will need to obtain permission directly from the copyright holder. To view a copy of this licence, visit http://creativeco mmons.org/licenses/by/4.0/. 
A method for measuring the mass, density, and Young's modulus of a specimen without needing to weigh the specimen was developed based on a frequency equation that incorporates the effect of an additional mass attached to a wooden bar [1-6]. This method is referred to as the vibration method with additional mass (VAM) in this study. This method utilizes decreases in the resonance frequency by attaching additional mass. The ratio of the resonance frequency with the additional mass to that without it is used in the frequency equation incorporating the effect of the concentrated mass attached to a specimen and its position. The mass ratio (concentrated mass/specimen) is subsequently calculated using the frequency equation.

To analyze the potential application of the VAM for practical purposes, a series of parameters were investigated, including the suitable mass ratio (additional mass/specimen) [7], the connection between the additional mass and specimen [7], the crossers' position for the piled lumber [8], the specimen moisture content [9], and the bending vibration generation method [10]. The VAM could perhaps be used to assess the deterioration of the cross beams of timber guardrails [11] and the mass of the piled lumber [12]. The estimation accuracy of the VAM decreased with an increase in the effect of shear and rotatory inertia, and it could be corrected [13].

Our previous study [14] showed that a cut end portion could be used as the virtual mass in the VAM. In this study, we investigate whether the use of a cut end portion in the VAM can be applied to a log. First, the VAM was applied to the circular truncated cone used as the model of a log. Next, a cut end portion was used for the virtual additional mass in the VAM using a circular truncated cone and log.

\section{Theory}

\section{Longitudinal vibration for a circular truncated cone with a concentrated mass}

A circular truncated cone of radii of $r_{1}$ and $r_{2}\left(r_{1} \geq r_{2}, k\right.$ is the ratio of $r_{2}$ to $\left.r_{1}, k=r_{2} / r_{1}\right)$ and length $l$ with concentrated mass $M$ placed at $\left(x_{1}, x_{2}\right)=(a l, 0)$ shown in Fig. 1 is considered. Herein, longitudinal vibration under the free-free condition is considered.

A circular truncated cone is prepared by rotating segments $\mathrm{AB}$ and $\mathrm{BC}$ about the $x$ axis as shown in Fig. 1. The equations for the segments $\mathrm{AB}$ and $\mathrm{BC}$ are:

Segment $\mathrm{AB}$ :

$$
\begin{aligned}
& y_{1}=p_{1} x_{1}+q_{1}\left(0 \leq x_{1} \leq a l\right) . \\
& p_{1}=\frac{(k-1) r_{1}}{l} . \\
& q_{1}=r_{1} .
\end{aligned}
$$

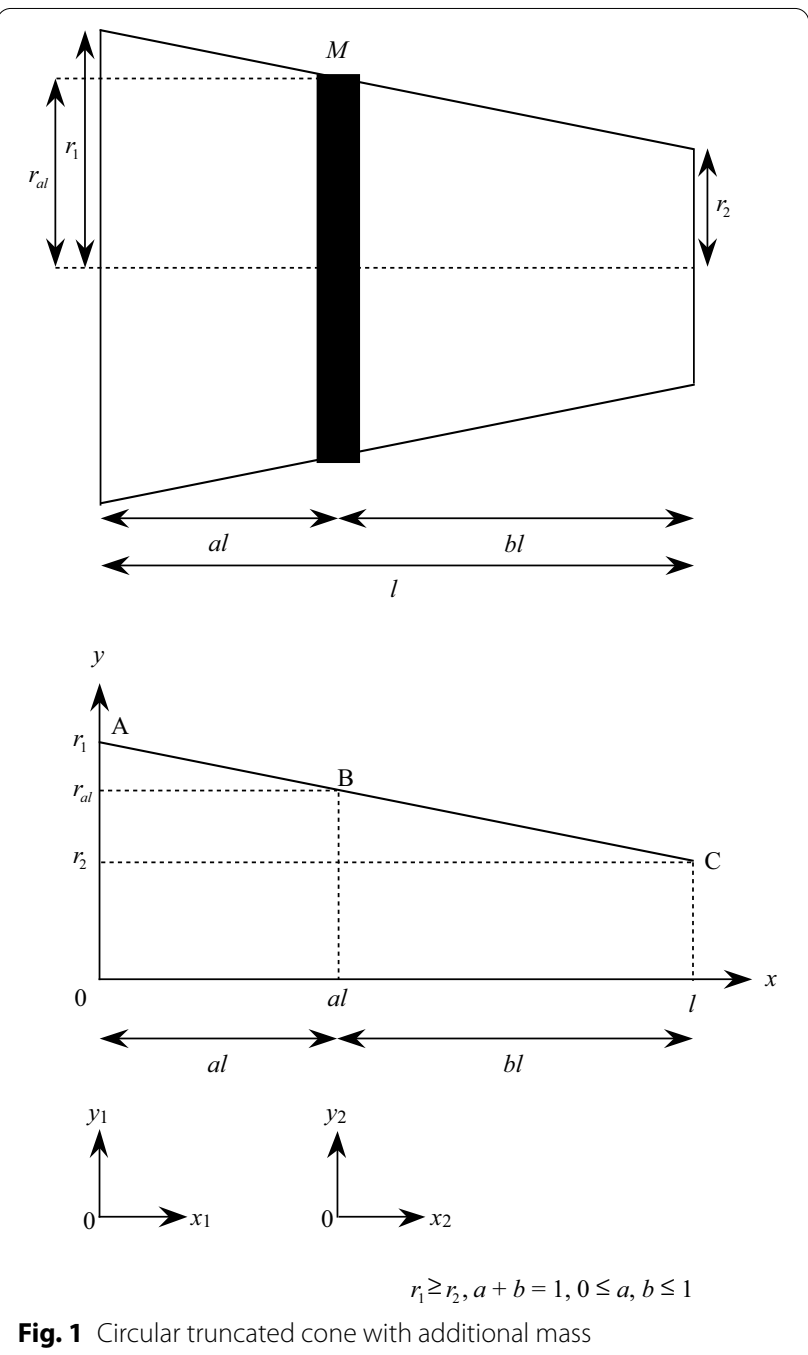

Segment BC:

$$
\begin{aligned}
& y_{2}=p_{2} x_{2}+q_{2}\left(0 \leq x_{2} \leq b l\right) . \\
& p_{2}=p_{1} . \\
& q_{2}=r_{1}\{(k-1) a+1\} .
\end{aligned}
$$

The longitudinal displacements $u_{1}\left(x_{1}, t\right)$ and $u_{2}\left(x_{2}, t\right)$ are represented as

$$
\begin{aligned}
& u_{1}\left(x_{1}, t\right)=v_{1}\left(x_{1}\right) \sin \omega_{n} t \\
& v_{1}\left(x_{1}\right)=\frac{C_{11}}{p_{1} x_{1}+q_{1}} \sin \left(\sqrt{\frac{\rho}{E}} \omega_{n} x_{1}+C_{21}\right), \\
& u_{2}\left(x_{2}, t\right)=v_{2}\left(x_{2}\right) \sin \omega_{n} t
\end{aligned}
$$




$$
v_{2}\left(x_{2}\right)=\frac{C_{12}}{p_{2} x_{2}+q_{2}} \sin \left(\sqrt{\frac{\rho}{E}} \omega_{n} x_{2}+C_{22}\right),
$$

where $C_{11}, C_{21}, C_{12}$, and $C_{22}$ are constants, $t, \rho, E$, and $\omega$ (equal to $2 \pi f$, where $f$ is the resonance frequency) are time, density, Young's modulus, and angular frequency, and the subscript $n$ is the mode number.

Because the axial force does not exist at each extremity under a free-free condition:

$$
\left\{\begin{array}{l}
x_{1}=0: \frac{\partial u_{1}}{\partial x_{1}}=0 \\
x_{2}=b l: \frac{\partial u_{2}}{\partial x_{2}}=0
\end{array}\right.
$$

Because both parts of the bar are connected and the difference in the axial force in each bar is equal to the inertia force exerted by the concentrated mass at $\left(x_{1}\right.$, $\left.x_{2}\right)=(a l, 0)$

$$
\left\{\begin{array}{c}
u_{1}=u_{2} \\
E S\left(x_{2}\right) \frac{\partial u_{2}}{\partial x_{2}}-E S\left(x_{1}\right) \frac{\partial u_{1}}{\partial x_{1}}=M \frac{\partial^{2} u_{1}}{\partial t^{2}}=M \frac{\partial^{2} u_{2}}{\partial t^{2}}
\end{array}\right.
$$

where $S$ is cross-sectional area.

From Eqs. (7)-(12)

\section{Longitudinal vibration testing method without weighing the specimen}

The resonance frequency, represented by $f_{n 0}(0$ : value without the additional mass), is expressed as follows:

$$
f_{n 0}=\frac{m_{n 0}}{2 \pi l} \sqrt{\frac{E}{\rho}}
$$

where $m_{n 0}$ is a constant depending on $k$ for a circular truncated cone from Eq. (15).

The resonance frequency is decreased experimentally by attaching the additional mass, whereas, the dimensions, density, and Young's modulus are not altered. Hence, it can be said that $m_{n 0}$ changes to $m_{n}$. The resonance frequency after attaching the additional mass is expressed as follows:

$$
f_{n}=\frac{m_{n}}{2 \pi l} \sqrt{\frac{E}{\rho}}
$$

From Eqs. (17) and (18)

$$
m_{n}=\frac{f_{n}}{f_{n 0}} m_{n 0}
$$

The measured resonance frequencies $f_{n 0}$ and $f_{n}$ are substituted in Eq. (19) to calculate $m_{n}$, and the calculated $m_{n}$

$$
\left\{(k-1)^{2}+k m_{n}^{2}\right\} \tan m_{n}-m_{n}(k-1)^{2}+\frac{1}{3} \mu m_{n} \frac{k^{2}+k+1}{\{(k-1) a+1\}^{2}} \frac{\left\{m_{n}+(k-1) \tan a m_{n}\right\}\left\{k m_{n}+(k-1) \tan b m_{n}\right\}}{1-\tan a m_{n} \tan b m_{n}}=0
$$

where $\mu$ is the ratio of the concentrated mass to the mass of the circular truncated cone and is defined as

$$
\mu=\frac{M}{\frac{1}{3} \pi\left(r_{1}^{2}+r_{1} r_{2}+r_{2}^{2}\right) l \rho}=\frac{3 M}{\pi\left(k^{2}+k+1\right) r_{1}^{2} l \rho}
$$

Equation (13) is the frequency equation for a circular truncated cone with a concentrated mass.

i. If $\mu=0$, then Eq. (13) is as follows [15]:

$$
\left\{(k-1)^{2}+k m_{n}^{2}\right\} \tan m_{n}-m_{n}(k-1)^{2}=0
$$

ii. If $k=1$, then Eq. (13) is as follows [3]:

$$
\sin m_{n}+\mu m_{n} \cos a m_{n} \cos b m_{n}=0 .
$$

is substituted in Eq. (13) to calculate $\mu$. A specimen mass and density can be obtained by substituting the calculated $\mu$, the concentrated mass, and the dimensions of the bar in Eq. (14). The Young's modulus can be calculated by substituting the estimated density, resonance frequency without the concentrated mass, and dimensions of the bar in Eq. (17) [1-6].

The above steps represent the calculation procedure for the VAM. The mass of the specimen is not required for the calculations.

\section{Materials and methods Specimens}

Air-dried, 1000-mm length, circular truncated cones (larger diameter, smaller diameter $)=(100 \mathrm{~mm}, 90 \mathrm{~mm})$, (100 mm, $80 \mathrm{~mm}),(100 \mathrm{~mm}, 70 \mathrm{~mm}),(100 \mathrm{~mm}, 60 \mathrm{~mm})$, $(100 \mathrm{~mm}, 50 \mathrm{~mm}),(100 \mathrm{~mm}, 40 \mathrm{~mm})$, and $(100 \mathrm{~mm}$, 
$30 \mathrm{~mm}$ ) were produced from Sitka spruce (Picea sitchensis Carr.) with a cross section of $110 \mathrm{~mm}$ square and a length of $1500 \mathrm{~mm}$ without a pith. The circular truncated cone is a model of a log and differs from an actual log in that the circular truncated cone has the slope grain. The larger and smaller diameter ends are referred as to butt end and top end, respectively, in this study. Two specimens were made for each dimension. The specimens were conditioned at $20{ }^{\circ} \mathrm{C}$ and $65 \%$ relative humidity. The vibration tests for the Sitka spruce circular truncated cones were conducted under the same conditions.

In addition, six Japanese cedar (Cryptomeria japonica D. Don) logs with bark having a length of $3000 \mathrm{~mm}$ and the larger diameter of about 190-260 $\mathrm{mm}$ and the smaller diameter of about $160-210 \mathrm{~mm}$ planted in the Forestry and Forest Products Research Institute (Tsukuba, Japan) were used as specimens. Their tree ages were 16,32 , and 41 years. Japanese cedar logs were used within two days after felling. The vibration tests for the Japanese cedar logs were conducted in a sawmill building without controlling temperature and relative humidity. The cut end portions of the logs were weighed before the vibration tests and oven-dried at $105^{\circ} \mathrm{C}$.

\section{Vibration tests}

Free-free longitudinal vibration tests were conducted for the following three purposes.

First, to experimentally prove the theory of the VAM for the circular truncated cones mentioned above, the free-free longitudinal vibration tests were conducted on the circular truncated cones with the length of $1000 \mathrm{~mm}$ with/without the concentrated mass. The concentrated mass was attached to the butt end $(x=0)$ or the top end $(x=l)$. Iron plates with dimensions $25 \mathrm{~mm} \times 15 \mathrm{~mm} \times 2 \mathrm{~mm}$, mass $5.4 \mathrm{~g}$ (M1) and that with the dimensions of $25 \mathrm{~mm} \times 25 \mathrm{~mm} \times 2 \mathrm{~mm}$, mass $10.0 \mathrm{~g}$ (M2) were used for the concentrated masses. The concentrated masses M3, M4, M5, and M6 were made by laminating 2, 3, 4, and $5 \mathrm{M} 2$ iron plates using the doublesided tapes in the thickness direction, respectively.

Second, to experimentally examine the use of cut end portions in the VAM, the free-free longitudinal vibration tests were conducted on the circular truncated cones. One specimen was cut from the butt end and the other was cut from the top end. All the specimens were cut at the distances of $10 \mathrm{~mm}$ until the length was $700 \mathrm{~mm}$. The longitudinal vibration tests were performed, while the specimens were shortened stepwise.

Third, to experimentally examine the application of the VAM to the logs, the free-free longitudinal vibration tests were conducted. Three logs were cut from the butt end and the other three were cut from the top end of a specimen. All the logs were cut at the distances of $50 \mathrm{~mm}$

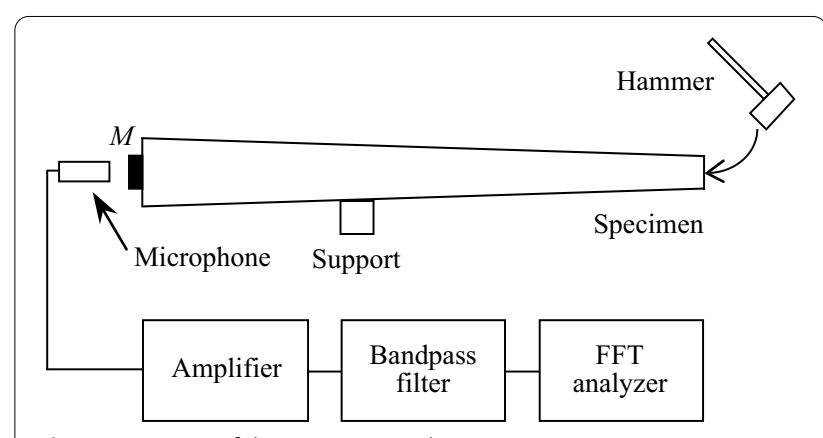

Fig. 2 Diagram of the experimental setup

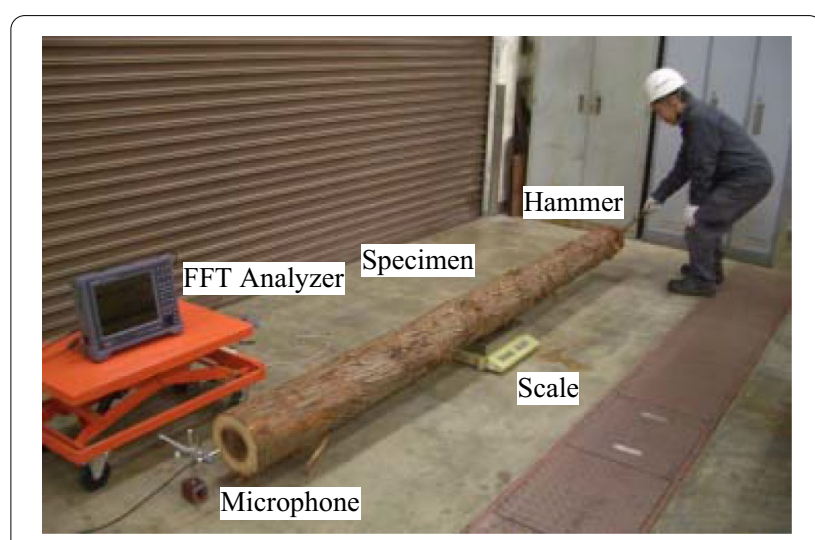

Fig. 3 Vibration test for the logs

until the length was $2850 \mathrm{~mm}$. The longitudinal vibration tests were performed, while the specimen was shortened stepwise.

The free-free longitudinal vibration tests were performed using the following procedure: the test bar was placed on a support near its center point. Next, longitudinal vibration was generated by tapping the RT-plane of one end in the L-direction using a hammer with an iron-head, and the first-mode vibration of the specimen was detected using a microphone (PRECISION SOUND LEVEL METER 2003, NODE Co., Ltd, Tokyo, Japan) placed at the other end. The signal was processed using a Fast Fourier Transform (FFT) digital signal analyzer (Multi-Purpose FFT Analyzer CF-5220, Ono-Sokki, Co., Ltd., Yokohama, Japan) to observe the high-resolution resonance frequencies. The diagram of the experimental setup and the photograph of the vibration test for the logs are shown in Figs. 2 and 3, respectively.

\section{Results and discussion}

The mean (standard deviation) density and Young's modulus of the initial specimens before cutting were 480 (23) $\mathrm{kg} / \mathrm{m}^{3}, 15.45$ (0.98) GPa (Sitka spruce), and 878 (121) kg/ 
$\mathrm{m}^{3}, 5.13$ (1.61) GPa (Japanese cedar), respectively. The mean (standard deviation), maximum, minimum moisture content of the cut end portion of Japanese cedar log were 172 (34), 238, and 133\%, respectively.

The estimation accuracy of the VAM was expressed using the mass ratio (estimated specimen mass through the VAM/measured specimen mass) $M_{\mathrm{VAM}} / M_{0}$ and the estimation accuracy of VAM was considered to be sufficiently high when $0.9 \leq M_{\mathrm{VAM}} / M_{0} \leq 1.1$ in this study. Since the density and Young's modulus are proportional to mass and density, respectively, the ratio of the estimated density through the VAM to the measured density, and the ratio of the estimated Young's modulus through the VAM to the Young's modulus measured through the normal vibration test without the concentrated mass are equal to $M_{\mathrm{VAM}} / M_{0}$.

Table 1 shows the accuracy of the VAM for the circular truncated cones using the decrease in the resonance frequency by attaching the concentrated mass. The range of $\mu$ was from 0.000156 to 0.0347 , and $M_{\mathrm{VAM}} / M_{0}$ was from 0.9 to 1.1 in several $\mu$ values. Hence, it was possible to estimate the masses of the circular truncated cones with $10 \%$ error by the VAM. The estimation accuracy of VAM for the smaller concentrated mass was higher than that for the larger concentrated mass regardless of $k$. This tendency is explained in the same way as the uniform crosssection specimen using the relationship between $m_{n}$ and $\mu$ calculated from the frequency equation incorporating the effect of the concentrated mass attached to a specimen and its position $[3,5] . m_{n}$ decreases monotonically with respect to $\mu$, and the relationship between $m_{n}$ and $\mu$ is convex downward as shown in Fig. 4. Hence, the high estimation accuracy of VAM is likely to be obtained for the larger absolute value of the differential coefficient of the $m_{n}-\mu$ relationship i.e. for the smaller $\mu$ because the effect

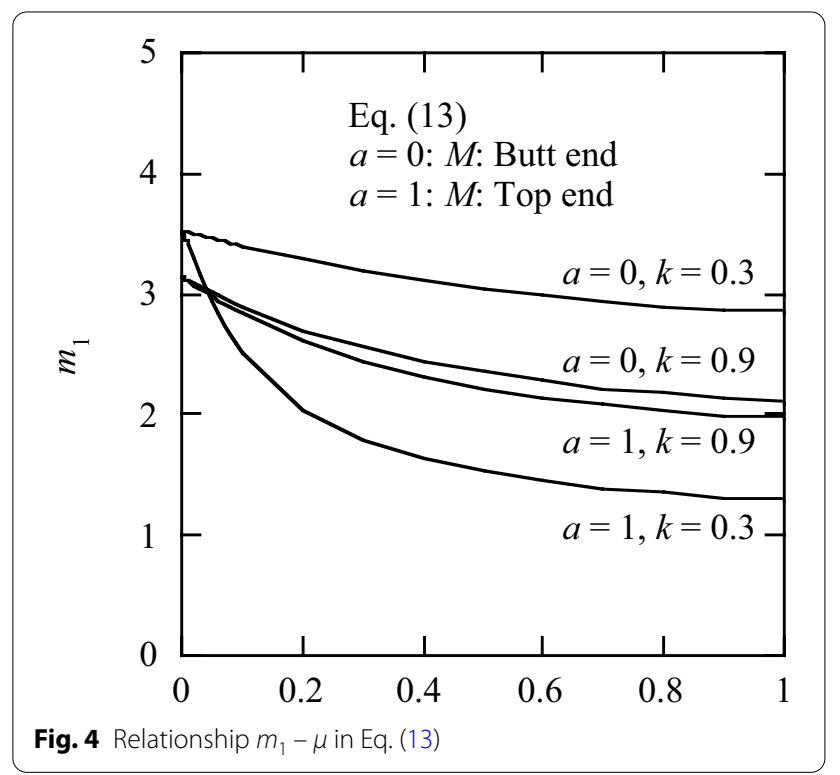

Table 1 Estimation acccuracy of the vibration method with additional mass (VAM) $M_{\mathrm{VAM}} / M_{0}$ for the circular truncated cones when the concentrated mass was placed at the butt end or the top end

\begin{tabular}{|c|c|c|c|c|c|c|c|c|c|c|c|c|c|c|}
\hline \multirow{3}{*}{$\begin{array}{l}\text { Diameter } \\
\text { of the top end } \\
{[\mathrm{mm}]}\end{array}$} & \multicolumn{7}{|c|}{$\begin{array}{l}\text { Attaching concentrated mass } \\
\text { to the butt end }\end{array}$} & \multicolumn{7}{|c|}{$\begin{array}{l}\text { Attaching concentrated mass } \\
\text { to the top end }\end{array}$} \\
\hline & \multicolumn{7}{|c|}{ Concentrated mass } & \multicolumn{7}{|c|}{ Concentrated mass } \\
\hline & M1 & M2 & M3 & M4 & M5 & M6 & Total & M1 & M2 & M3 & M4 & M5 & M6 & Total \\
\hline \multirow[t]{2}{*}{30} & 1.28 & 1.05 & 1.24 & 0.96 & 0.94 & 0.97 & 5 & 0.68 & 0.73 & 0.60 & 0.61 & 0.42 & 0.55 & 3 \\
\hline & 1.18 & 1.12 & 1.04 & 0.87 & 0.76 & 0.63 & & 1.19 & 1.11 & 1.02 & 0.94 & 0.86 & 0.96 & \\
\hline \multirow[t]{2}{*}{40} & 1.01 & 0.86 & 0.82 & 0.78 & 0.69 & 0.75 & 2 & 0.93 & 0.86 & 0.85 & 0.79 & 0.93 & 0.74 & 4 \\
\hline & 1.33 & 0.86 & 0.90 & 0.83 & 0.68 & 0.66 & & 0.94 & 0.91 & 0.86 & 0.83 & 0.73 & 0.69 & \\
\hline \multirow[t]{2}{*}{50} & 1.07 & 1.22 & 0.99 & 0.86 & 0.74 & 1.48 & 2 & 0.90 & 0.80 & 0.79 & 0.75 & 0.65 & 0.82 & 3 \\
\hline & 0.70 & 0.89 & 0.82 & 0.69 & 0.70 & 0.69 & & 0.89 & 0.93 & 0.83 & 0.68 & 0.96 & 0.73 & \\
\hline \multirow[t]{2}{*}{60} & 0.96 & 0.83 & 0.75 & 0.81 & 0.80 & 0.82 & 3 & 1.02 & 0.86 & 0.88 & 0.74 & 0.63 & 0.61 & 5 \\
\hline & 1.08 & 1.29 & 1.11 & 0.84 & 0.74 & 0.94 & & 0.92 & 0.91 & 0.97 & 0.92 & 0.66 & 0.81 & \\
\hline \multirow[t]{2}{*}{70} & 1.06 & 0.95 & 0.84 & 0.82 & 0.76 & 0.72 & 4 & 1.03 & 0.87 & 0.89 & 0.76 & 0.76 & 0.69 & 3 \\
\hline & 0.81 & 0.90 & 0.96 & 0.85 & 0.75 & 0.73 & & 0.79 & 0.96 & 1.07 & 0.88 & 0.74 & 0.77 & \\
\hline \multirow[t]{2}{*}{80} & 0.44 & 0.49 & 0.92 & 0.84 & 1.08 & 1.38 & 4 & 0.64 & 0.67 & 0.88 & 0.95 & 0.63 & 0.60 & 2 \\
\hline & 0.96 & 0.96 & 0.87 & 0.80 & 0.70 & 0.69 & & 0.97 & 0.83 & 0.84 & 0.74 & 0.81 & 0.64 & \\
\hline \multirow[t]{2}{*}{90} & 0.95 & 0.86 & 0.98 & 0.84 & 0.70 & 0.73 & 5 & 0.98 & 0.90 & 0.85 & 0.81 & 0.71 & 0.69 & 3 \\
\hline & 1.64 & 0.90 & 0.96 & 0.94 & 0.86 & 0.70 & & 1.49 & 0.97 & 0.81 & 0.86 & 0.66 & 1.12 & \\
\hline Total & 7 & 5 & 7 & 2 & 2 & 2 & & 8 & 6 & 3 & 3 & 2 & 1 & \\
\hline
\end{tabular}

$M_{\text {VAM }}$ : Estimated mass by the VAM, $M_{0}$ : Mesasured mass, Upper row of the same diameter: Specimen 1, Lower row of the same diameter: Specimen 2 , Total: Total number of occurrences of $0.9 \leq M_{\mathrm{VAM}} / M_{0} \leq 1.1$ 
of any errors in $m_{n}$ caused by measuring the resonance frequency on $\mu$ can be ignored. There was not a clear tendency between the estimation accuracy of VAM and $k$.

Figures 5 and 6 demonstrate the estimation accuracy of the VAM when the butt end portion or the top end portion of the circular truncated cones was cut. The initial properties (dimensions, mass and resonance frequency)
When the range of $a l \leq x \leq l$ in Fig. 1 is the end portion, i.e. when the top end is cut, the radius ratio (top end/but end) of the main body is

$$
k_{\mathrm{EC}}=\frac{r_{a l}}{r_{1}}=(k-1) a+1 .
$$

The volume ratio (end portion/main body) is

$$
\mu_{\mathrm{v}}=\frac{\frac{\pi}{3} b l\left(r_{a l}^{2}+r_{a l} r_{2}+r_{2}^{2}\right)}{\frac{\pi}{3} a l\left(r_{1}^{2}+r_{1} r_{a l}+r_{a l}^{2}\right)}=\frac{1-a}{a} \frac{\{(k-1) a+1\}^{2}+\{(k-1) a+1\} k+k^{2}}{\{(k-1) a+1\}^{2}+(k-1) a+2} .
$$

for the length of $1000 \mathrm{~mm}$ and properties after cutting correspond to the values with/without the concentrated mass in the section "Longitudinal vibration testing method without weighing the specimen", respectively. For accuracy, $\mu$ was calculated by

$$
\mu_{\mathrm{M}}=\frac{M_{\mathrm{i}}-M_{\mathrm{cut}}}{M_{\mathrm{cut}}}
$$

where $M_{\mathrm{i}}$ and $M_{\text {cut }}$ are the initial specimen mass, and specimen mass after end cutting, respectively.

$m_{n 0}$ was obtained by substituting $k$ in Eq. (15). Equation (15) was solved using a software [16].

$M_{\mathrm{VAM}} / M_{0}$ decreased when the specimens were shortened. Several results deviated from the $M_{\mathrm{VAM}} / M_{0}-$ length curve at the beginning of the shortening the specimen because the change in the resonance frequency was small. These tendencies were similar to those of the specimens with constant cross-sectional shapes [14].

The estimation accuracy reduced with the decreasing specimen length (Figs. 5 and 6). The effect of the decrease in the specimen length on the accuracy of estimation was explored theoretically.

The specimens can be divided into two parts: the end portion and the main body. The ratio of the mass (end portion/main body) is obtained. Dimensions of the main body and end portion are shown in Table 2 .

When the range of $0 \leq x \leq a l$ in Fig. 1 is the end portion, i.e. when the butt end is cut, the radius ratio (top end/butt end) of the main body is

$$
k_{\mathrm{EC}}=\frac{r_{2}}{r_{a l}}=\frac{k}{(1-k) b+k}
$$

where the subscript EC means "end cut".

The volume ratio (end portion/main body) is

$$
\mu_{\mathrm{v}}=\frac{\frac{\pi}{3} a l\left(r_{1}^{2}+r_{1} r_{a l}+r_{a l}^{2}\right)}{\frac{\pi}{3} b l\left(r_{a l}^{2}+r_{a l} r_{2}+r_{2}^{2}\right)}=\frac{1-b}{b} \frac{\{(1-k) b+k\}^{2}+(1-k) b+k+1}{\{(1-k) b+k\}^{2}+\{(1-k) b+k\} k+k^{2}} .
$$

Substituting the initial values before cutting the end (resonance frequency: $f_{n \mathrm{i}}$, constant: $m_{n \mathrm{i}}$, and length: $l_{\mathrm{i}}$ ) for Eq. (18):

$$
f_{n \mathrm{i}}=\frac{m_{n \mathrm{i}}}{2 \pi l_{\mathrm{i}}} \sqrt{\frac{E}{\rho}}
$$

Substituting the values after cutting the end (resoEq. (17),

$$
f_{\text {ncut }}=\frac{m_{n \mathrm{cut}}}{2 \pi l_{\mathrm{cut}}} \sqrt{\frac{E}{\rho}}
$$

Substituting $f_{n \mathrm{i}}$ and $f_{n c u t}$ for Eq. (19), $m_{n}$ to be substituted for Eq. (13) is

$$
m_{n}=\frac{f_{n \mathrm{i}}}{f_{n \mathrm{cut}}} m_{n \mathrm{cut}}=\frac{l_{\text {cut }}}{l_{\mathrm{i}}} m_{n \mathrm{i}}
$$
Eq. (13) is written as $\mu_{\text {cut }}$ the accuracy of the VAM is

$$
\frac{M_{\mathrm{VAM}}}{M_{0}}=\frac{\mu_{\mathrm{V}}}{\mu_{\mathrm{cut}}} .
$$

The ratio $M_{\mathrm{VAM}} / M_{0}$ is plotted against the specimen length ratio (after/before end cutting) (Figs. 7 and 8). The experimental estimations had high overlap with the theoretical estimations. To maintain high estimation accuracy, a specimen length must not be too short as shown in our previous study for a specimen with the constant cross-sectional shape [14]. From the theoretical analysis, the estimation accuracy was more than 0.90 when the nance frequency: $f_{n \text { cut }}$, constant: $m_{n \text { cut }}$, and length: $\left.l_{\text {cut }}\right)$ for

If the $\mu$ calculated by substituting $m_{\mathrm{n}}$ from Eq. (27) for 

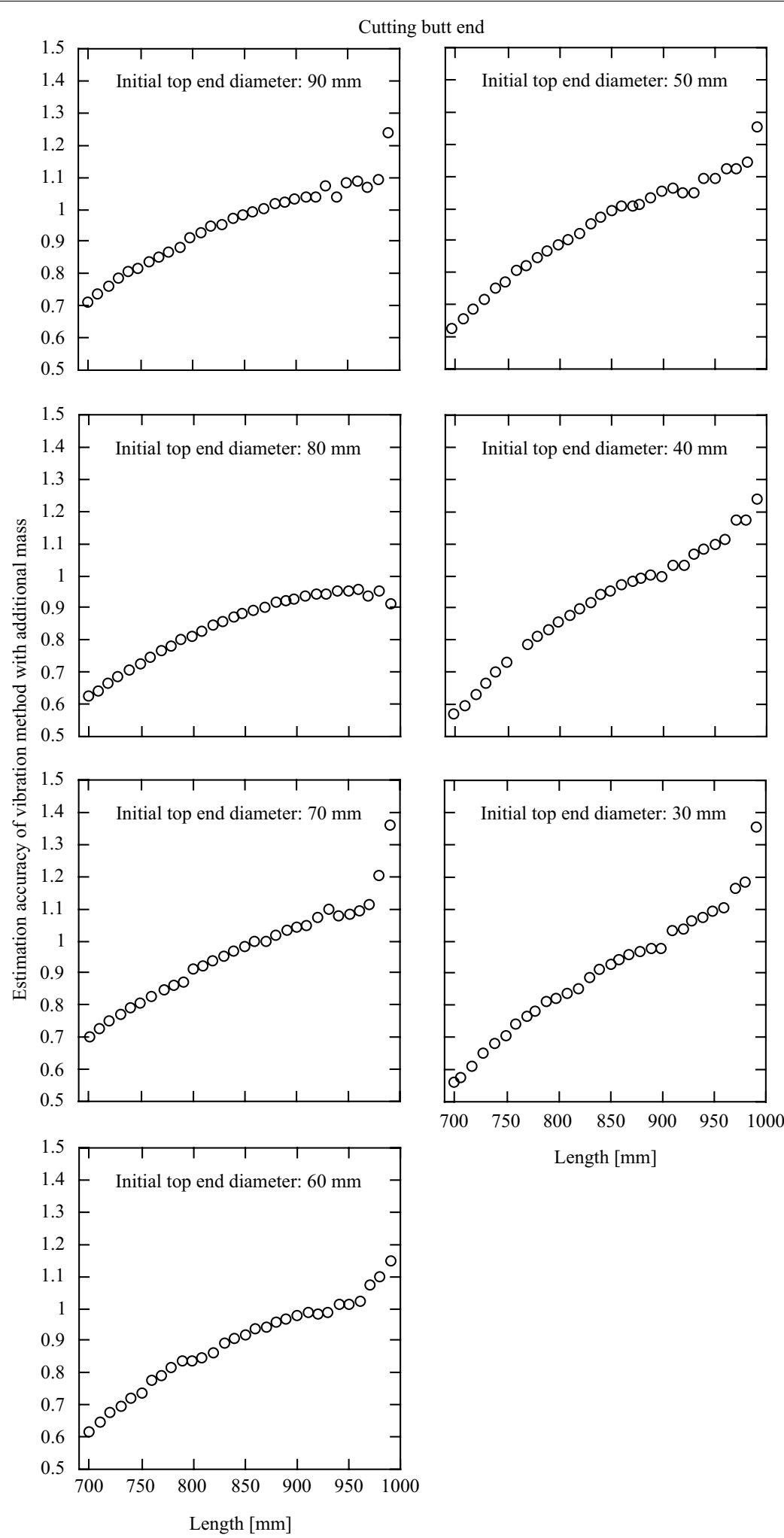

Fig. 5 Experimental estimation acccuracy of the vibration method with additional mass (VAM) $M_{V A M} / M_{0}\left(M_{\text {VAM }}\right.$ : Estimated mass by the VAM, $M_{0}$ : Mesasured mass) for the circular truncated cones when the cut butt end portion was used for the virtual additional mass 

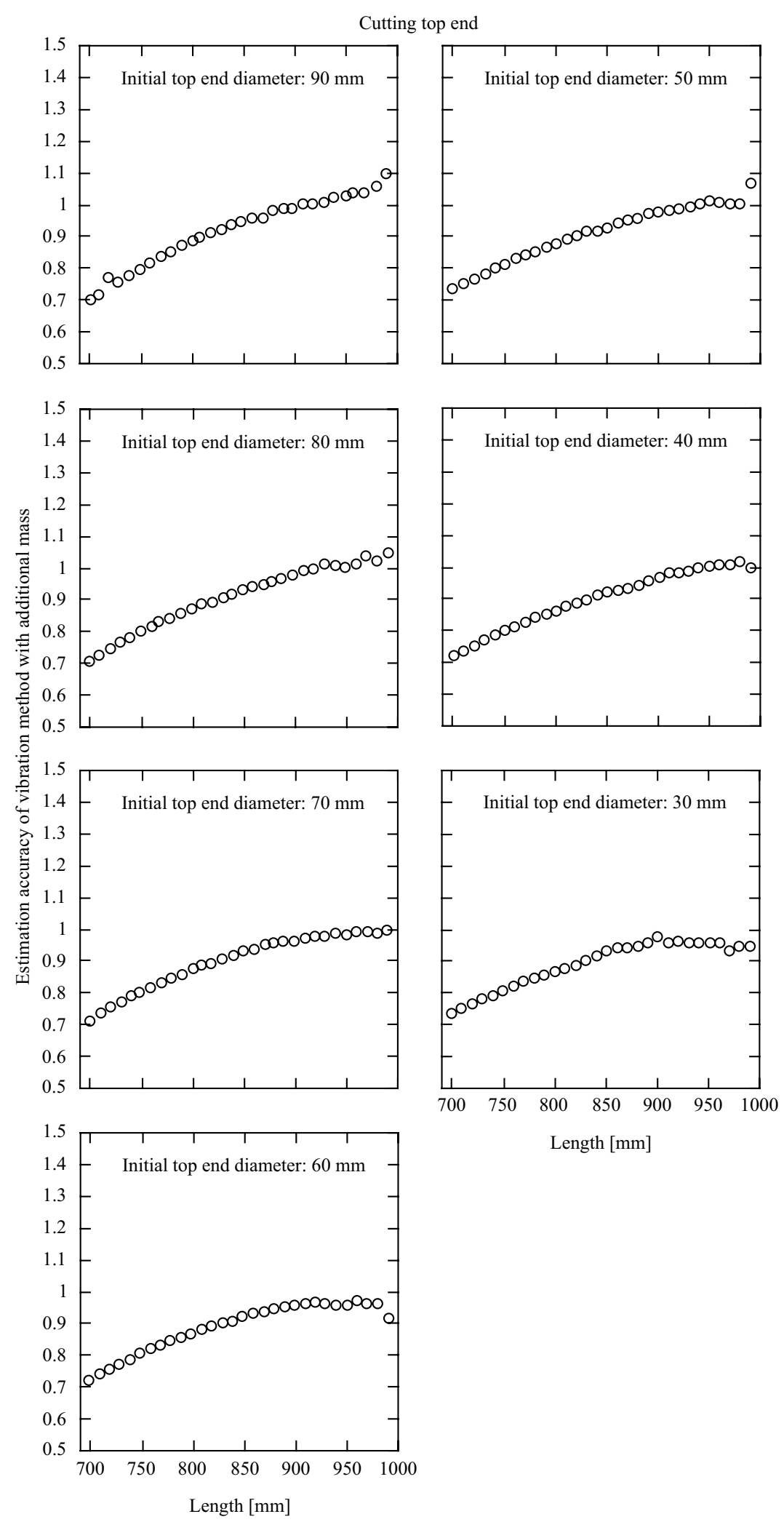

Fig. 6 Experimental estimation acccuracy of the vibration method with additional mass (VAM) $M_{\text {VAM }} / M_{0}\left(M_{\text {VAM: }}\right.$ : Estimated mass by the VAM, $M_{0}$ : Mesasured mass) for the circular truncated cones when the cut top end portion was used for the virtual additional mass 
Table 2 Dimensions of the main body and the end portion of the circular truncated cones

\begin{tabular}{lll}
\hline Cutting butt end (End portion: $0 \leq \boldsymbol{x} \leq \boldsymbol{a l}$ ) & \\
\hline & Main body & End portion \\
\hline Butt end radius & $r_{a l}$ & $r_{1}$ \\
Top end radius & $r_{2}$ & $r_{a l}$ \\
Length & $b l$ & $a l$
\end{tabular}

Cutting top end (End portion: $a l \leq x \leq l$ )

\begin{tabular}{lll}
\hline & Main body & End portion \\
\hline Butt end radius & $r_{1}$ & $r_{a l}$ \\
Top end radius & $r_{a l}$ & $r_{2}$ \\
Length & al & $b l$
\end{tabular}

$r_{a l}=\{(k-1) a+1\} r_{1}=\{(1-k) b+k\} r_{1}$

specimen length ratio was more than 0.855 for the butt end cut and 0.826 for the top end cut.

Table 3 shows the mass of the Japanese cedar logs estimated by the VAM. The calculation procedure is the same as that for the circular truncated cones. It can be said that $M_{\mathrm{VAM}} / M_{0}$ was 0.9 or more. Hence, it is possible that the mass of a log can be simply estimated using a cut end portion with the sufficient accuracy. Since the estimation accuracy was sufficiently high when the cutting length was from 50 to $150 \mathrm{~mm}$, the high estimation accuracy will be obtained by cutting the aforementioned extra length.

We consider the application of the VAM to on-site logs. Since $m_{n 0}$ depends on $k$, it is necessary to contain a process to calculate an $m_{n 0}$ or an $m_{n 0}-k$ table in the
VAM. Although the logs were placed on a support near their center point, i.e., the nodal position of the first mode of the longitudinal vibration, the logs will be supported by at least two points on-site. Hence, the number of supporting points (the resonance mode of the longitudinal vibration to be used) and materials to be used for the supporting points need to be examined in the future.

\section{Conclusions}

Longitudinal vibrations were undertaken and the VAM was applied to the circular truncated cones and logs. The following results were obtained.

1. From the results of the vibration test using specimens with/without the concentrated mass, it was possible to estimate the mass of a circular truncated cone with $10 \%$ error by the VAM.

2. The cut butt end and the cut top end portions of a circular truncated cone could be used as the virtual mass in the VAM.

3. From the experimental results and theoretical results, in order to maintain high estimation accuracy, a specimen length must not be too short as shown in our previous study for a specimen with the constant cross-sectional shape.

4. The cut butt end and the cut top end portions of a log could be used as the virtual mass in the VAM. Hence, it is possible to simply measure the mass of log without weighing the log itself on site through a vibration test. 

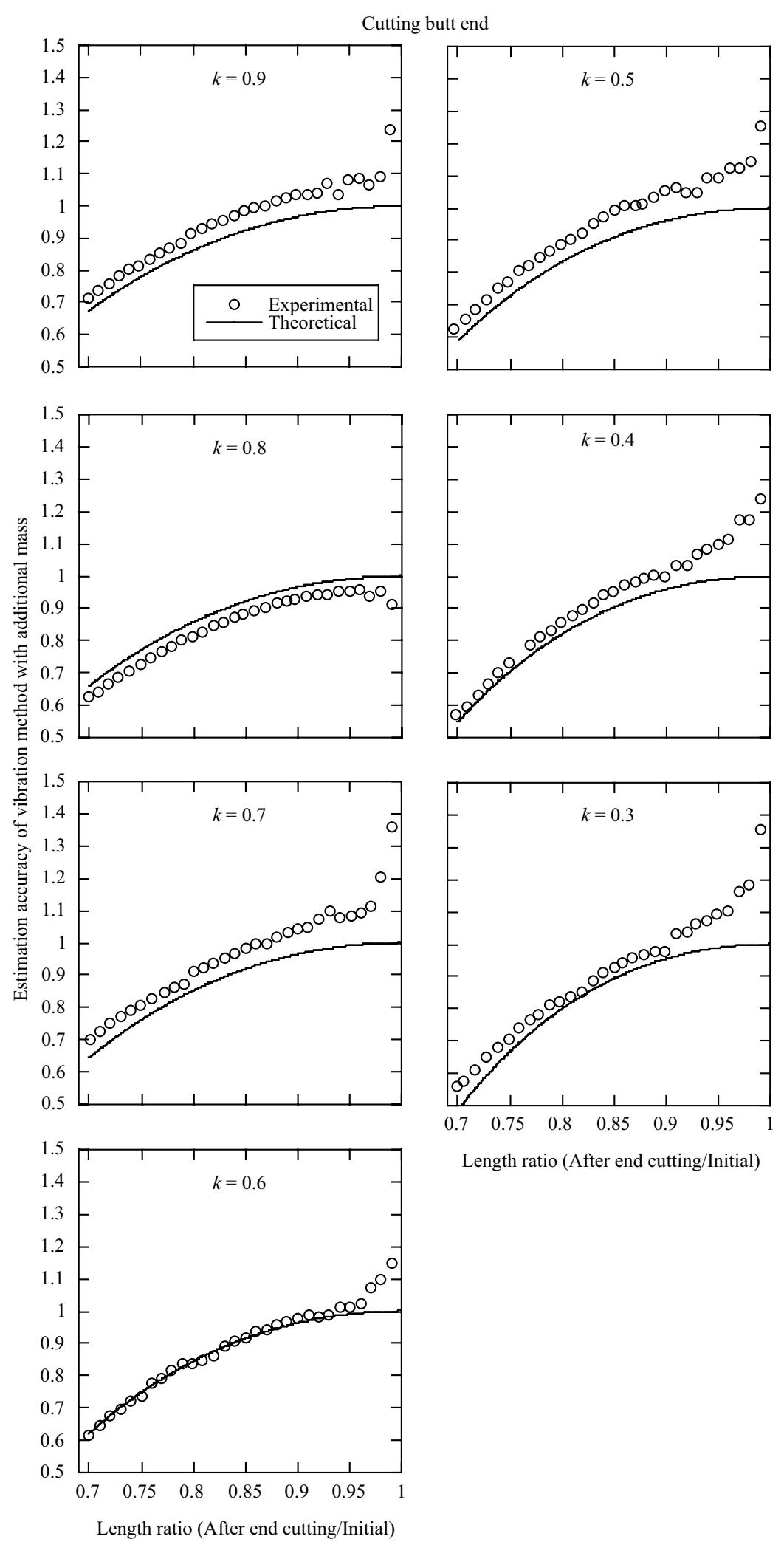

Length ratio (After end cutting/Initial)

Fig. 7 Theoretical estimation acccuracy of the vibration method with additional mass (VAM) $M_{\text {VAM }} / M_{0}\left(M_{\text {VAM }}\right.$ : Estimated mass by the VAM, $M_{0}$ : Mesasured mass) for the circular truncated cone when the cut butt end portion was used for the virtual additional mass 

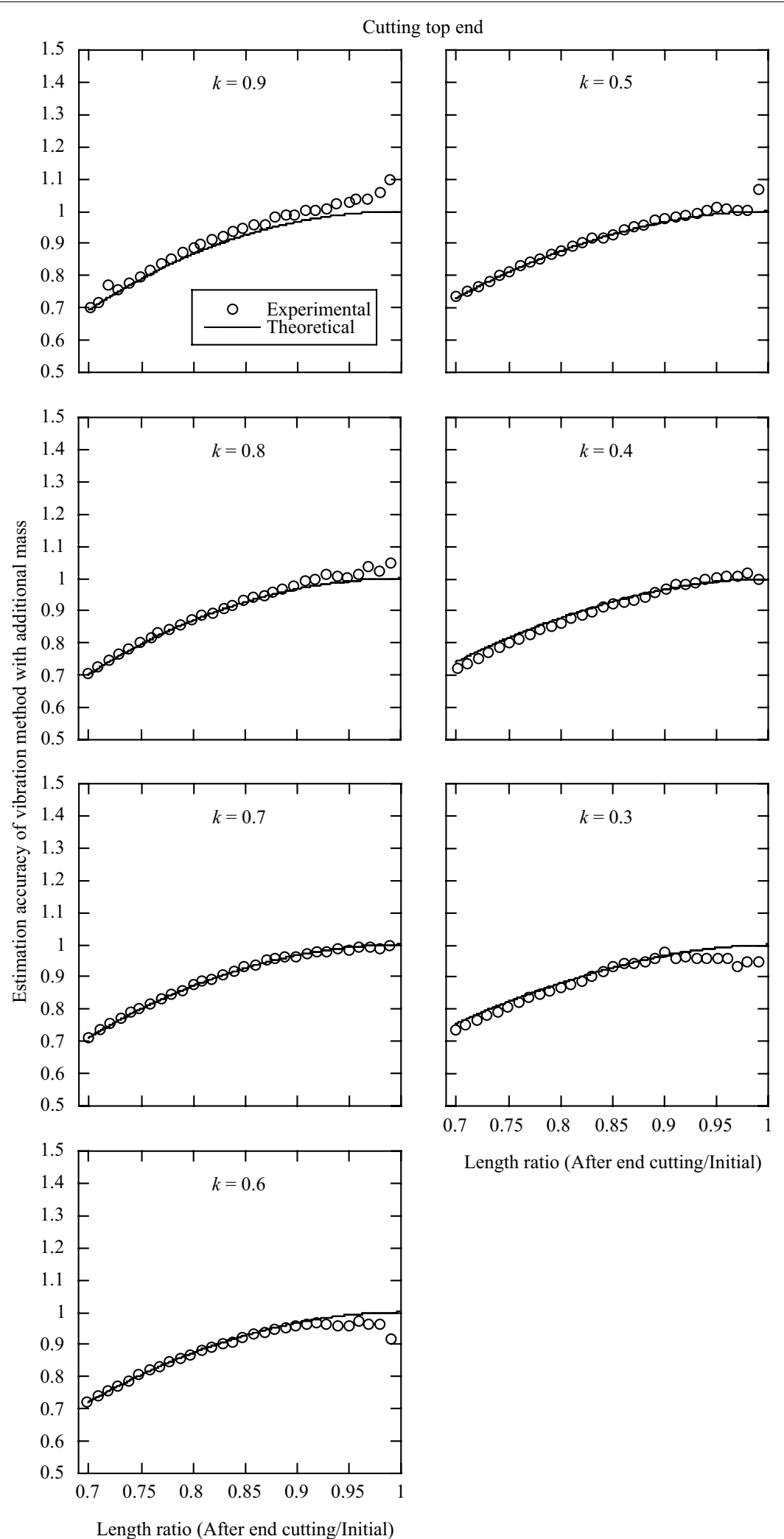

Length ratio (After end cutting/Initial) 
Table 3 Estimation acccuracy of the vibration method with additional mass (VAM) for logs when the butt end or top end were cut

\begin{tabular}{|c|c|c|c|c|c|c|c|c|}
\hline \multirow[t]{2}{*}{ Specimen } & \multicolumn{2}{|c|}{$\begin{array}{l}\text { Circumference of end } \\
(\mathrm{mm})\end{array}$} & \multirow[t]{2}{*}{ Length (mm) } & \multirow[t]{2}{*}{$\begin{array}{l}\text { Measured } \\
\text { Mass } M_{0}(g)\end{array}$} & \multirow[t]{2}{*}{ Frequency $(\mathrm{Hz})$} & \multirow[t]{2}{*}{$m_{n 0}$} & \multirow{2}{*}{$\begin{array}{l}\text { Estimated mass } \\
\text { by the VAM } \\
M_{\text {VAM }}(\mathrm{g})\end{array}$} & \multirow[t]{2}{*}{$M_{\text {VAM }} / M_{0}$} \\
\hline & Butt & Top & & & & & & \\
\hline \multicolumn{9}{|c|}{ Cutting the butt end } \\
\hline \multirow[t]{4}{*}{1} & 809 & 658 & 3009.0 & 108,540 & 440.700 & 3.15511 & Initial & Initial \\
\hline & 802 & 658 & 2948.0 & 105,440 & 452.700 & 3.15400 & 93,247 & 0.88 \\
\hline & 790 & 658 & 2891.0 & 102,660 & 463.650 & 3.15219 & 92,871 & 0.90 \\
\hline & 778 & 658 & 2832.0 & 100,040 & 474.950 & 3.15050 & 90,102 & 0.90 \\
\hline \multirow[t]{4}{*}{2} & 681 & 570 & 3082.5 & 84,340 & 372.200 & 3.15163 & Initial & Initial \\
\hline & 678 & 570 & 3020.0 & 82,540 & 379.550 & 3.15114 & 76,620 & 0.93 \\
\hline & 676 & 570 & 2963.5 & 80,740 & 387.000 & 3.15082 & 75,790 & 0.94 \\
\hline & 674 & 570 & 2899.5 & 78,920 & 395.200 & 3.15050 & 72,893 & 0.92 \\
\hline \multirow[t]{4}{*}{3} & 612 & 505 & 3014.5 & 49,500 & 371.400 & 3.14962 & Initial & Initial \\
\hline & 605 & 505 & 2964.5 & 48,220 & 380.550 & 3.14851 & 44,727 & 0.93 \\
\hline & 600 & 505 & 2903.0 & 46,840 & 392.050 & 3.14775 & 41,039 & 0.88 \\
\hline & 579 & 505 & 2841.5 & 45,520 & 404.550 & 3.14501 & 39,000 & 0.86 \\
\hline \multicolumn{9}{|c|}{ Cutting the top end } \\
\hline \multirow[t]{4}{*}{4} & 611 & 506 & 3004.0 & 74,000 & 482.200 & 3.15286 & Initial & Initial \\
\hline & 611 & 514 & 2961.0 & 73,180 & 488.800 & 3.15107 & 71,585 & 0.98 \\
\hline & 611 & 513 & 2906.0 & 71,980 & 499.100 & 3.15129 & 69,060 & 0.96 \\
\hline & 611 & 517 & 2850.0 & 70,960 & 506.950 & 3.15045 & 70,285 & 0.99 \\
\hline \multirow[t]{4}{*}{5} & 697 & 569 & 3022.0 & 95,500 & 384.750 & 3.15463 & Initial & Initial \\
\hline & 697 & 566 & 2975.0 & 94,400 & 390.150 & 3.15532 & 97,210 & 1.03 \\
\hline & 697 & 564 & 2922.0 & 92,960 & 398.000 & 3.15579 & 91,954 & 0.99 \\
\hline & 697 & 550 & 2852.0 & 91,820 & 404.050 & 3.15933 & 93,970 & 1.02 \\
\hline \multirow[t]{4}{*}{6} & 611 & 488 & 3016.0 & 58,660 & 339.550 & 3.15758 & Initial & Initial \\
\hline & 611 & 504 & 2963.5 & 57,780 & 346.550 & 3.15334 & 52,106 & 0.90 \\
\hline & 611 & 478 & 2907.5 & 56,900 & 353.400 & 3.16064 & 55,803 & 0.98 \\
\hline & 611 & 490 & 2849.0 & 56,060 & 360.300 & 3.15701 & 53,490 & 0.95 \\
\hline
\end{tabular}

\section{Abbreviations}

VAM: Vibration method with additional mass; L: Longitudinal; R: Radial; T: Tangential; FFT: Fast Fourier Transform.

\section{Acknowledgements}

We thank Dr. Tokihiko Nanjo and Mr. Kazunori Arai of Research Planning and Coordination Department, Forestry and Forest Research Institute (FFPRI) and Dr. Yuichiro Oribe of Genetic Resources Department, Forest Tree Breeding Center, FFPRI for their help in providing the logs.

This study was presented in part at the 37th Annual Meeting of Wood Technological Association of Japan, Hiroshima, September 2019.

\section{Authors' contributions}

All authors designed the experiments. YK performed the experiments, analyzed the data, and was a major contributor in writing the manuscript. All authors contributed to interpretation and discussed results. All authors read and approved the final manuscript.

\section{Funding}

Not applicable.

\section{Availability of data and materials}

All data generated or analyzed during this study are included in this published article.
Competing interests

The authors declare that they have no competing interests.

\section{Author details}

${ }^{1}$ Forestry and Forest Products Research Institute, 1 Matsunosato, Tsukuba, Ibaraki 305-8687, Japan. ${ }^{2}$ Forestry \& Fisheries Research Center, Toyama Prefectural Agricultural, 4940 Kurokawa Shin, Imizu, Toyama 939-0311, Japan.

Received: 3 September 2020 Accepted: 19 November 2020

Published online: 12 January 2021

\section{References}

1. Skrinar M (2002) On elastic beams parameter identification using eigenfrequencies changes and the method of added mass. Computational Mater Sci 25:207-217

2. Türker T, Bayraktar A (2008) Structural parameter identification of fixed end beams by inverse method using measured natural frequencies. Shock Vib 15:505-515

3. Kubojima Y, Sonoda S (2015) Measuring Young's modulus of a wooden bar using longitudinal vibration without measuring its weight. Eur J Wood Wood Prod 73:399-401 
4. Matsubara M, Aono A, Kawamura S (2015) Experimental identification of structural properties of elastic beam with homogeneous and uniform cross section. Trans JSME 81:831. https://doi.org/10.1299/trans jsme.15-00279

5. Kubojima Y, Kato H, Tonosaki M, Sonoda S (2016) Measuring Young's modulus of a wooden bar using flexural vibration without measuring its weight. BioRes 11:800-810

6. Matsubara M, Aono A, Ise T, Kawamura S (2016) Study on identification method of line density of the elastic beam under unknown boundary conditions. Trans JSME 82:837. https://doi.org/10.1299/trans jsme.15-00669

7. Sonoda S, Kubojima Y, Kato H (2016) Practical techniques for the vibration method with additional mass Part 2: Experimental study on the additional mass in longitudinal vibration test for timber measurement. In: CD-ROM Proceedings of the World Conference on Timber Engineering (WCTE 2016), Vienna, Austria, August 22-25, 2016

8. Kubojima Y, Sonoda S, Kato H (2017a) Practical techniques for the vibration method with additional mass: effect of crossers' position in longitudinal vibration. J Wood Sci 63:147-153

9. Kubojima Y, Sonoda S, Kato H (2017b) Practical techniques for the vibration method with additional mass: effect of specimen moisture content. J Wood Sci 63:568-574

10. Kubojima Y, Sonoda S, Kato H (2018a) Practical techniques for the vibration method with additional mass: bending vibration generated by tapping cross section. J Wood Sci 64:16-22
11. Kubojima Y, Sonoda S, Kato H (2018b) Application of the vibration method with additional mass to timber guardrail beams. J Wood Sci 64:767-775

12. Kubojima Y, Sonoda S, Kato H (2020) Mass of piled lumber estimated through vibration test. J Wood Sci 66:32. https://doi.org/10.1186/s1008 6-020-01880-5

13. Kubojima Y, Sonoda S, Kato H, Harada M (2020) Effect of shear and rotatory inertia on the bending vibration method without weighing specimens. J Wood Sci 66:51. https://doi.org/10.1186/s10086-020-01900 $-4$

14. Kubojima Y, Sonoda S, Kato H (2019) Use of cut specimen pieces in the vibration method with additional mass (VAM). J Wood Sci 65:30. https:// doi.org/10.1186/s10086-019-1807-3

15. Kubojima Y, Matsumura Y, Suzuki Y (2018) Longitudinal vibration test for the use of a circular truncated cone as a log model of Japanese cedar. BioRes 13:1035-1041

16. Wolfram Research Co., Ltd. (2016) Mathematica version 10.4J

\section{Publisher's Note}

Springer Nature remains neutral with regard to jurisdictional claims in published maps and institutional affiliations.

\section{Submit your manuscript to a SpringerOpen ${ }^{\circ}$ journal and benefit from:}

- Convenient online submission

$\checkmark$ Rigorous peer review

- Open access: articles freely available online

- High visibility within the field

- Retaining the copyright to your article

Submit your next manuscript at $\boldsymbol{\nabla}$ springeropen.com 